\title{
High Prevalence of Human-Associated Escherichia coli in Wetlands Located in Eastern France
}

\author{
Daniel Martak ${ }^{1,2 *}$, Charles P. Henriot ${ }^{2}$, Marion Broussier ${ }^{1}$, Charlotte Couchoud ${ }^{1,2}$, \\ Benoit Valot ${ }^{2,3}$, Marion Richard ${ }^{1}$, Julie Couchot ${ }^{1}$, Gudrun Bornette ${ }^{2}$, Didier Hocquett ${ }^{1,2,3}$ \\ and Xavier Bertrand ${ }^{1,2}$ \\ ${ }^{1}$ Service d'Hygiène Hospitalière, Centre Hospitalier Universitaire, Besançon, France, ${ }^{2}$ UMR 6249, Laboratoire \\ Chrono-Environnement, CNRS-Université de Bourgogne Franche-Comté, Besançon, France, ${ }^{3}$ Bioinformatique et big data \\ au service de la santé, UFR Santé, Université de Bourgogne Franche-Comté, Besançon, France
}

Escherichia coli that are present in the rivers are mostly brought by human and animal feces. Contamination occurs mostly through wastewater treatment plant (WWTP) outflows and field amendment with sewage sludge or manure. However, the survival of these isolates in river-associated wetlands remains unknown. Here, we assessed E. coli population structure in low-anthropized wetlands located along three floodplains to identify the major source of contamination of wetlands, whose functioning is different from the rivers. We retrieved $179 \mathrm{E}$. coli in water samples collected monthly from 19 sites located in eastern France over 1 year. Phylogroups B1 and B2 were dominant in the E. coli population, while phylogroup A was dominant in isolates resistant to thirdgeneration cephalosporins, which harbored the extended-spectrum $\beta$-lactamase (ESBL) encoding genes bla of isolates from human source can be attributed to WWTP outflows and the spread of sewage sludge. We analyzed the distribution of the isolates belonging to the most human-associated phylogroups (B2 and D) on a phylogenetic tree of the whole species and compared it with that of isolates retrieved from patients and from WWTP outflows. The distribution of the three E. coli populations was similar, suggesting the absence of a specific population in the environment. Our results suggest that a high proportion of E. coli isolates that reach and survive in low-anthropized environments such as wetlands are from human source. To the best of our knowledge, this is the first study assessing E. coli contamination and resistance genes in natural freshwater wetlands.

Keywords: floodplains, wetlands, E. coli, human-associated E. coli, wastewater treatment plant

\section{INTRODUCTION}

Escherichia coli is a facultative anaerobic organism commensal of the vertebrate gut microbiota. Paradoxically, it can also be responsible of infections and is one of the main pathogens responsible for hospital- and community-acquired infections (Tenaillon et al., 2010). Pathogenic strains of E. coli are divided into intestinal pathogens causing diarrhea and extraintestinal E. coli (ExPEC) 
causing a variety of infections in both humans and animals including urinary tract infections, meningitis, and septicemia (Johnson et al., 2003; Riley, 2014). Although the ExPEC major clone sequence type (ST) 131 became predominant and have spread worldwide, other clones are also frequent (i.e., ST10, ST38, ST69, ST73, and ST405) (Nicolas-Chanoine et al., 2014; Manges et al., 2019). In contrast, diarrheagenic E. coli have been clustered into different pathovars according to their virulence gene arsenal. Humans widely contribute to the dissemination of $E$. coli in the environment through wastewaters. In developed countries, these wastewaters are treated in wastewater treatment plants (WWTPs). However, WWTP outflows contain E. coli that are released to the rivers (Bréchet et al., 2014). Agriculture also contributes to $E$. coli dissemination through practices such as spreading manure or sewage sludge (Cabral, 2010; Niu and Phanikumar, 2015; Hocquet et al., 2016). Cattle also play an important role in the dissemination of E. coli in the environment through their feces (Cabral, 2010). Overall, E. coli contaminates nearly all environments, with both human-associated or not human-associated $E$. coli present in rivers, lakes, groundwater, plants, and soils (Brookes et al., 2004; John and Rose, 2005; Park et al., 2016).

E. coli clusters into phylogroups A, B1, B2, C, D, E, F, and G (Clermont et al., 2013, 2019). Strains belonging to phylogroups $\mathrm{A}$ and $\mathrm{B} 1$ are ubiquitous and adapted to humans or vertebrate animals. Phylogroup A strains are predominant in humans while B1 strains are predominant in animals (Berthe et al., 2013). The rare phylogroup $\mathrm{C}$ is closely related to phylogroup B1 (Moissenet et al., 2010). Strains belonging to phylogroups B2, D, and F are the most frequent phylogroups found in human ExPEC infections (Clermont et al., 2013).

Extended-spectrum $\beta$-lactamase (ESBL) is the major cause of resistance to cephalosporins in E. coli. In recent decades, ESBL-producing $E$. coli have spread worldwide, becoming a serious public health threat (Pitout and Laupland, 2008). These resistant strains have been widely isolated from humans but also from animals and food sources (Mughini-Gras et al., 2019; Pärnänen et al., 2019). In a One-Health perspective, many recent studies assessed the relationships between $E$. coli from humans, meat, livestock, and WWTPs to understand the role played by humans in the spread of E. coli (Day et al., 2019; Ludden et al., 2019). Here, we wanted to understand the fate of E. coli in low-anthropized environments by determining the E. coli population structure in three rivers and their associated wetlands. We further compared their population structure with those from clinical settings and of WWTP outflows to understand the dynamics of the E. coli phylogroups from the human source to the wetlands.

\section{MATERIALS AND METHODS}

\section{Bacterial Sampling}

We sampled 16 wetlands distributed along the lower floodplains of the Ain, Doubs and Loue Rivers, three karstic rivers of the Jura Massif in eastern France (Supplementary Figure 1). One sampling point per river was chosen to compare the wetlands and the rivers. Each river and its associated wetlands were sampled monthly for 1 year (from March 2015 to March 2016). Samples of $250 \mathrm{~mL}$ of water were collected and $100 \mathrm{~mL}$ of water were filtered by $0.45 \mu \mathrm{m}$ membranes and deposited on Drigalski agar plates (DRIGs) (Oxoid) and on ESBL-producing bacteria selection plates (chromID ESBL plates; bioMérieux, Marcy l'Etoile, France). After an overnight incubation at $37^{\circ} \mathrm{C}$, colonies were counted; each lactose positive bacteria cultured on DRIGs and colonies growing on ESBL-specific plates were identified by MALDI-TOF MS (Microflex 100 LT; Bruker Daltonik GmbH, Bremen, Germany). All E. coli identified with a $\log$ value $\geq 2$ according to the manufacturer's recommendations and with different morphotypes were stored at $-80^{\circ} \mathrm{C}$ until further analysis.

\section{Identification of $b / a_{E S B L}$ in Isolates Resistant to Third-Generation Cephalosporins (3GC-R)}

For each morphotype of E. coli growing on chromID ESBL plates, we confirmed the production of ESBL with the synergy test recommended by the Antibiogram Committee of the French Society for Microbiology (CA-SFM ${ }^{1}$, last consultation: 10 November 2018). We used E. coli reference strain ATCC 25922 as a control. Isolates with a negative synergy test were considered as producer of plasmid-mediated cephalosporinases. Hence, isolates that grow on ESBL selective plates (i.e., resistant to 3GC) were sorted into ESBL or plasmid-mediated cephalosporinase producers. For all ESBL-producing isolates, we identified bla $a_{\mathrm{ESBL}}$ genes by PCR and sequencing. We first screened the isolates carrying bla $a_{\mathrm{CTX}-\mathrm{M}}$ with consensus primers and we then targeted the different groups of CTX-M with specific primers (bla $a_{\mathrm{CTX}}$-M-group 1, bla $a_{\mathrm{CTX}-\mathrm{M} \text {-group 9, }}$ bla $a_{\mathrm{CTX}-\mathrm{M} \text {-group 2 }}$ ). bla $a_{\mathrm{CTX}-\mathrm{M}}$ negative isolates were then tested for the presence of bla

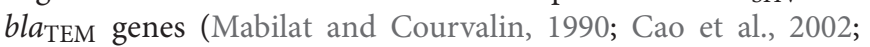
Coque et al., 2008). The nucleotide sequences of all PCR products were determined.

\section{Molecular Typing}

Bacterial DNA was extracted from an overnight culture on Mueller-Hinton agar (Bio-Rad, Marne la Coquette, France) using the boiling method. We used the Clermont method to assign all the isolates to one of the eight existing phylogroups (A, B1, B2, C, D, E, F, G) (Clermont et al., 2013, 2019). Phylogroups were assigned depending on the presence/absence of four genes $(\operatorname{arp} A$, chuA, yjaA, and TspE4.C2) using a quadruplex PCR. Isolates with identical profiles were further discriminated by additional PCRs. Hence, we amplified $\operatorname{trp} A$ to differentiate the isolates in phylogroups $\mathrm{A}$ and $\mathrm{C}, \operatorname{arp} A$ to differentiate the isolates in phylogroups $\mathrm{D}$ and $\mathrm{E}$, and $c f a B$ and $y b g D$ to differentiate isolates of the phylogroups B2, F, and G. Particular profiles allowed us to differentiate E. coli and Escherichia cryptic clades (Clermont et al., 2013). Isolates belonging to phylogroups B2 or D were typed by multi-locus sequence typing (MLST) using a previously described method (Wirth et al., 2006).

\footnotetext{
${ }^{1}$ http://www.sfm-microbiologie.org/
} 


\section{Sequence Types Distribution}

The distribution of STs of interest was assessed with an SNPbased analysis of the concatenation of the seven alleles of 4195 STs extracted from EnteroBase (Alikhan et al., 2018). We built a phylogenetic tree with FastTree v2.1.9 (Price et al., 2009, 2010), with a GTR-G model to visualize the links between the different STs. Subtrees were then extracted using the R package ggtree (Yu et al., 2017, 2018) to precisely visualize the population structure of phylogroups B2 and D. STs found in clinical settings or in treated wastewater were extracted from previously published results (Gibreel et al., 2012; Bréchet et al., 2014; Kallonen et al., 2017). Their distribution on the trees was compared with that of the isolates retrieved from the floodplains.

\section{Statistical Analysis}

The independence of the explanatory variables of the whole dataset (i.e., spatial - floodplain and site variables) was tested using Pearson's $\chi^{2}$-tests on the contingency tables of each pair of explanatory variables. The explanatory variables were all independent of each other. Therefore, the independence of $(i)$ the phylogroups and (ii) the relationships between phylogroups mostly associated to human (B2, D, F) and other (A, B1, C, E) E. coli strains with respect to each explanatory variable (one by one) was tested. We first separately constructed contingency tables for $(i)$ the phylogroups and each explanatory variable and (ii) the association or not of the isolates with humans and each explanatory variable for $E$. coli cultured on DRIGs or ESBL selective plates. We then performed Pearson's $\chi^{2}$-tests on each contingency tables. The $\alpha$ value was set to 0.05 . All analyses were performed with R 3.5.1 software (R Core Team Package 2019).

\section{RESULTS}

We retrieved 179 isolates of $E$. coli. We cultured 125 isolates on DRIGs; these isolates represented the unselected E. coli population present in the different rivers and their associated wetlands. We also cultured water samples on selective plates and identified 54 3GC-R isolates of which 49 and 5 produced an ESBL and a plasmid-mediated cephalosporinase, respectively. We also found 29 isolates belonging to the Escherichia cryptic clades (Clermont et al., 2013).

\section{Phylogroup Distribution of the Unselected E. coli Population}

The phylogroup distribution of the unselected $E$. coli population (cultured on DRIGs) showed that isolates belonging to phylogroups B1 (32\%) and B2 (29.6\%) were predominant (Figure 1A), with a high proportion of B2 isolates in the Ain floodplain $(p=0.048)$. Isolates belonging to phylogroups $\mathrm{A}$ (19.2\%), C (6.4\%), and D (12\%) were identified in each floodplain, whereas isolates from phylogroup E $(0.8 \%)$ were identified from only the Ain floodplain.

\section{GC-R E. coli}

Compared to the other phylogroups, phylogroup A (39.6\%) was dominant in 3GC-R E. coli (Figure 1B; $p=0.002$ ). Phylogroups
C (18.9\%) and D (20.7\%) were more frequent than phylogroups B2 (11.3\%) and B1 (7.6\%). Phylogroup B1 was found only in the Ain and Loue floodplains, whereas phylogroup F (1.8\%) was only found in the Doubs floodplain. There were more isolates belonging to phylogroup $\mathrm{A}$ in the Loue and Doubs floodplains than in the Ain floodplain $(p=0.018)$. Isolates belonging to the phylogroups mostly associated to human (B2, D, and F) were less frequent than the other phylogroups $(p=0.019)$.

$b l a_{\mathrm{ESBL}}$ in $543 \mathrm{GC}-\mathrm{R}$ isolates were mostly bla $a_{\mathrm{CTX}-\mathrm{M}-15}$ (43\%) and bla $a_{\mathrm{CTX}-\mathrm{M}-1}$ (24\%). bla $a_{\mathrm{CTX}-\mathrm{M}-14}$ and bla $a_{\mathrm{CTX}-\mathrm{M}-27}$ represented 17 and $7 \%$ of the bla $a_{\mathrm{ESBL}}$ genes, respectively. The remaining 3-GC-R isolates (9\%) presumably produced a plasmidmediated cephalosporinase. Among the isolates belonging to the phylogroups mostly associated to human (B2, D; $n=17$ ), 47, 29, 12 , and $12 \%$ produced CTX-M-15, CTX-M-14, CTX-M-1, and plasmid-mediated cephalosporinase, respectively.

\section{MLST Typing of $E$. coli Belonging to Phylogroups B2 and D}

All phylogroup B2 and D isolates $(n=69)$ were typed by MLST. We obtained 31 different STs, nine of which were new STs (Supplementary Table 1). Twenty-six isolates belonged to STs often associated with humans (ST10, ST12, ST38, ST69, ST73, ST95, ST131, ST372, ST405).

A phylogenetic tree comprising 4195 STs extracted from EnteroBase (Alikhan et al., 2018) was built. Then, we extracted the phylogroup B2 and phylogroup D subtrees (Figures 3A,B, respectively). The subtrees showed that the isolates from clinical or environmental collections (WWTPs or floodplains) were scattered throughout the trees, indicating (i) that the structure of these populations was comparable and (ii) the absence of a specific population in the environment.

Three phylogroup B2 STs (ST95, ST131, and ST372) and four phylogroup D STs (ST38, ST69, ST362, ST405) were shared among the three different collection groups.

\section{Escherichia Cryptic Clades}

We retrieved 29 isolates belonging to Escherichia cryptic clades, which represents $14 \%$ of the isolates retrieved in this study. The Escherichia cryptic clades were predominant in wetlands not connected to rivers $(p=0.026)$.

\section{DISCUSSION}

\section{Phylogroup Distribution of the Unselected E. coli Population}

We previously determined that the concentration of total E. coli was higher in the rivers than in the wetlands with no significant differences in concentrations between wetlands (Henriot et al., 2019). We then divided $125 \mathrm{E}$. coli isolates into phylogroups and found a high proportion of isolates belonging to phylogroups $\mathrm{A}$ and B2, representing half of the isolates retrieved (48.8\%). It was unexpected to find mostly human-associated phylogroups in lowanthropized wetlands (Escobar-Páramo et al., 2004; Massot et al., 2016). Previous studies identified WWTPs, sewage sludge and 

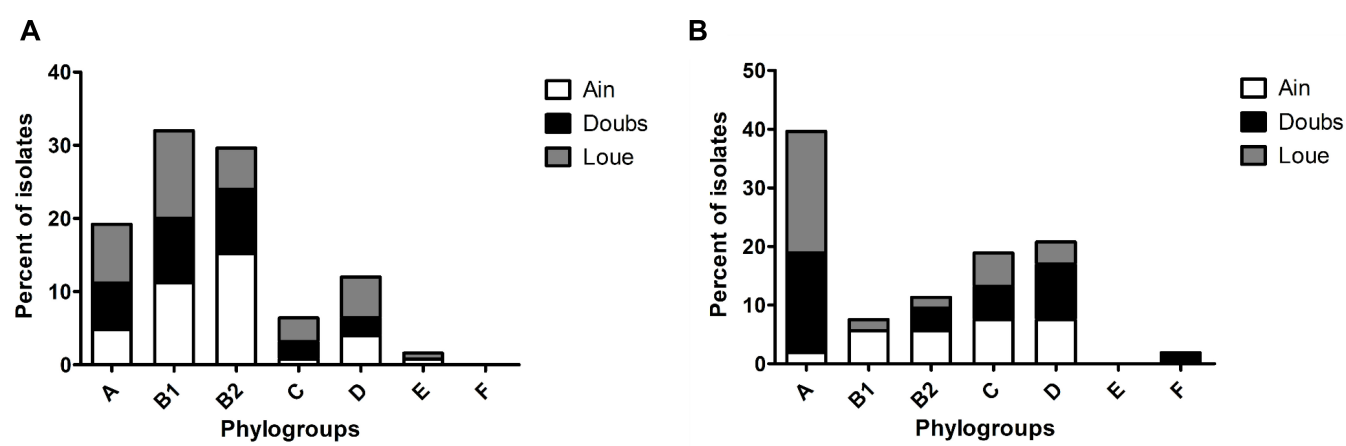

FIGURE 1 | Phylogroup distribution among the isolates retrieved from the three floodplains in eastern France. (A) Phylogroup distribution of the overall population of E. coli according to the floodplain. (B) Phylogroup distribution of 3GC-R E. coli according to the floodplain.

manure as sources of $E$. coli contamination in the environment (Michael et al., 2013; Balière et al., 2015). The contamination of the wetlands by isolates belonging to phylogroups $\mathrm{A}$ and B2 probably resulted from the release of WWTP outflows and the spread of sewage sludge. Phylogroup B1 is the main phylogroup found in animals (Gordon and Cowling, 2003). The high proportion of isolates belonging to this phylogroup (32\%) retrieved in the floodplains can be explained by direct contamination of the water by animals (wild animals or cattle, via superficial or groundwater flow) or by the spread of manure. Interestingly, the Ain floodplain was contaminated by a higher proportion of isolates belonging to phylogroup B2 than the Doubs and Loue floodplains (Figure 1A). This difference could be attributed to two concurrent factors in the Ain lower floodplain: a very coarse substrate (cobblestones) overlaid with a shallow soil layer and the spread of large amounts of sewage sludge. One can speculate that the spread of sewage sludge is a major source of contamination of the Ain River and wetlands by phylogroup B2 isolates, which are of human origin. However, this hypothesis needs to be confirmed by precise follow-up regarding the spread of sewage sludge and manure in each floodplain near the studied wetlands.

\section{Resistance and Phylogroup Distribution of 3GC-R E. coli}

Phylogroup A was the main phylogroup found in 3GC-R E. coli (39.6\%). These data are in line with the proportion of phylogroup A isolates recovered from humans (Tenaillon et al., 2010). This high proportion of isolates belonging to phylogroups A (39.6\%) and B2 (11.3\%) and the lower proportion of phylogroup B1 isolates (7.6\%) suggest that the contamination of rivers and wetlands by $3 \mathrm{GC}-\mathrm{R}$ E. coli could be caused more by human contamination rather than cattle contamination. The identification of bla $a_{\mathrm{ESBL}}$ genes showed that bla $a_{\mathrm{CTX}-\mathrm{M}-15}$ was predominant, accounting for $43 \%$ of the bla $a_{\mathrm{ESBL}}$ identified in the 3GC-R isolates (Figure 2). bla $a_{\mathrm{CTX}-\mathrm{M}-27}$ was present in $7 \%$ of the isolates. Together, bla $a_{\mathrm{CTX}-\mathrm{M}-15}$ and bla $a_{\mathrm{CTX}-\mathrm{M}-27}$ represented half of the bla $a_{\mathrm{ESBL}}$ found. These bla $a_{\mathrm{ESBL}}$ are highly related to E. coli found in humans (Day et al., 2019; Ludden et al., 2019).

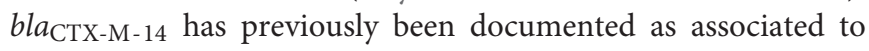

humans (Mughini-Gras et al., 2019), but this ESBL-encoding gene was also found in animals, especially in chicken (Hayashi et al., 2018). In contrast, bla $a_{\mathrm{CTX}-\mathrm{M}-1}$ is more often related to animals and meat (Day et al., 2019). This indicated that 3GCR E. coli that contaminate the floodplains mostly originated from human effluents released from WWTP outflows into the rivers (Oberlé et al., 2012; Bréchet et al., 2014). Many studies identified multidrug-resistant $E$. coli in rivers downstream large cities (Dhanji et al., 2011; Jang et al., 2013). Here, we found multidrug-resistant E. coli in areas that were far from any direct contamination by humans (i.e., up to $20 \mathrm{~km}$ downstream from the WWTP outflows in our case), suggesting that these isolates can survive in rivers despite long-distance dispersal by water.

\section{Escherichia Cryptic Clades}

The cryptic clades of $E$. coli comprise five different groups. Clade $\mathrm{I}$ is considered a divergent $E$. coli and has been reported in human infections, while the other clades are less virulent than clade I (Clermont et al., 2013). These cryptic clades are phenotypically indistinguishable from $E$. coli but genetically different.

The 29 isolates belonging to the cryptic clades retrieved in our study represented $14 \%$ of the isolates found. Previous studies found similar proportions of these isolates in environmental samples in Australia, France, and Italy (Walk, 2015). We found

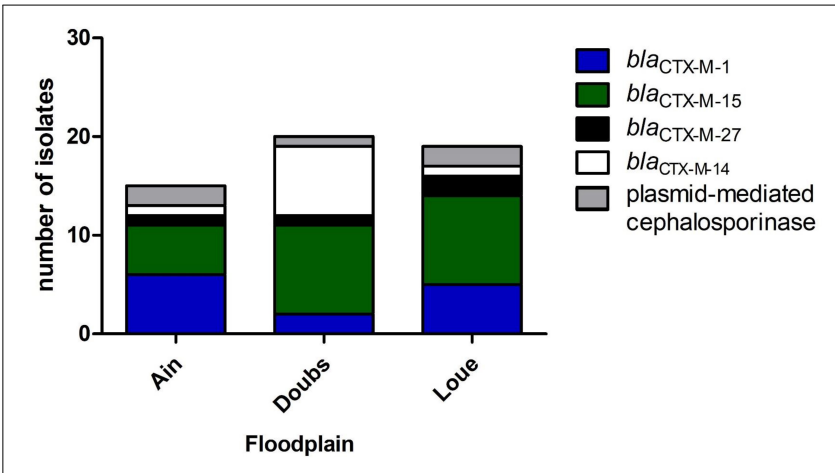

FIGURE 2 | Distribution of the genes conferring resistance to 3-GC among the $3 \mathrm{GC}-\mathrm{R}$ isolates retrieved from the three floodplains in eastern France $(n=54)$. 

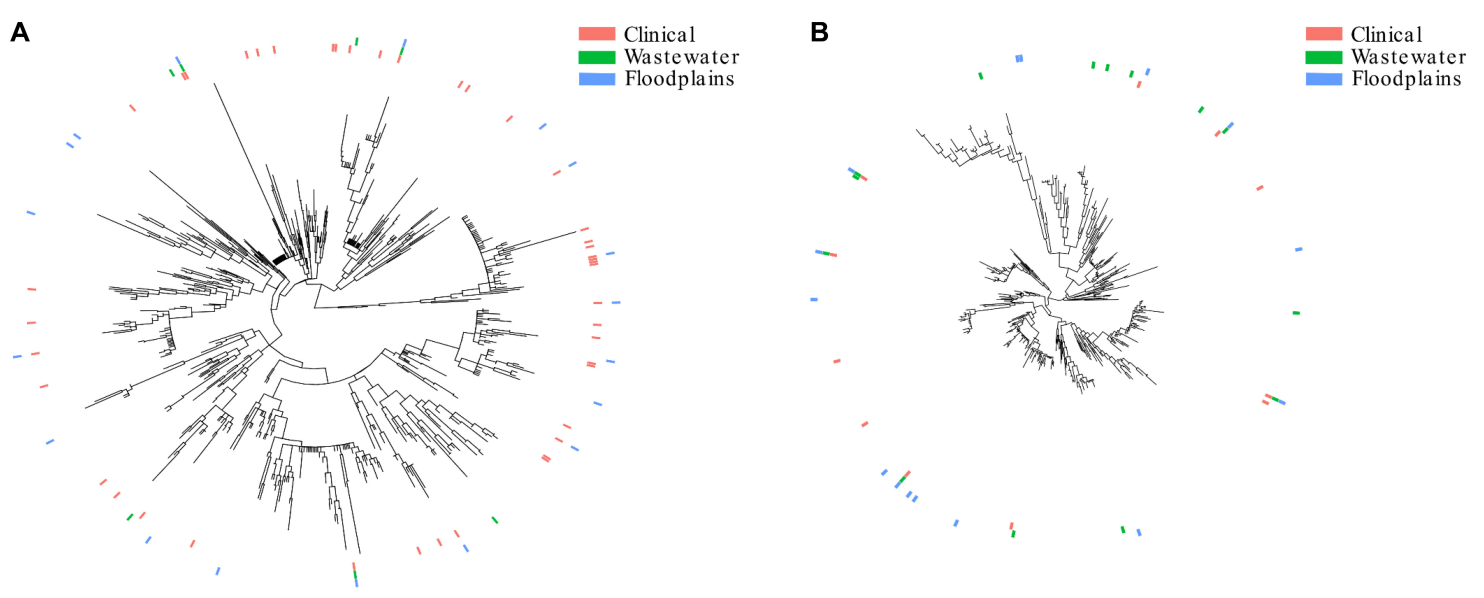

FIGURE 3 | Population structure of E. coli retrieved from the floodplains, clinical settings and wastewater treatment plants. (A) Subtree of the isolates belonging to phylogroup B2. (B) Subtree of the isolates belonging to phylogroup D. The presence of STs in clinical settings, WWTPs and floodplains are represented by pink, green and blue lines, respectively.

that these clades were frequent in unconnected wetlands which are supplied by groundwater, nutrient-poor, and cold (Bornette and Large, 1995; Bornette et al., 1996). In fact, low chlorophylla content, which directly relates to lower phytoplankton abundance and nutrient availability (Arthaud et al., 2013), and low temperature were nearly significantly associated with the presence of cryptic clades in wetlands of our study (data not shown). These cryptic clades may be genetically adapted to the environment by the presence of genes promoting their survival in this ecological niche (Walk, 2015).

\section{MLST Typing}

Among the B2 and D isolates, we found ST73, ST131, ST95, ST69, and ST12. These STs are predominant in isolates retrieved in the patient blood samples (Kallonen et al., 2017), further suggesting the human origin of the contamination.

The population structure of the present collection of E. coli was compared to that of collections from WWTP outflows and clinical settings (Figures 3A,B). Although not fully representative of all STs present in clinics or WWTPs, we found a comparable distribution of STs in the three collections that were distributed throughout the trees, suggesting that no specific sub-population of $E$. coli is adapted to a given environment. The similar distribution of STs in the WWTP outflows and in the environment strongly suggests that the contamination of the environment mostly results from the dilution of WWTP outflows. It also suggests that these isolates can reach and survive in remote areas like wetlands.

\section{E. coli Survival in Water}

Our results showed that low-anthropized wetlands contain E. coli isolates of human origin. Although E. coli contamination of rivers or lakes has been well-documented (Michael et al., 2013), that of wetlands has been less investigated. Indeed, the studied wetlands have varying degrees of connection with the river, can be supplied in water either by the river or by groundwater, and the physical and chemical parameters can vary from those of the river (Henriot et al., 2019). It has been reported that E. coli can survive and grow in the environment (Jang et al., 2017). However, its survival is influenced by many factors, such as the carbon sources, temperature, $\mathrm{pH}$, and availability of water (van Elsas et al., 2011). Here, we collected human-associated and 3GC-R isolates from a wide range of conditions (see Henriot et al., 2019 for details). Continuous discharge from WWTPs could explain the high proportion of human-associated E. coli isolates retrieved in low-anthropized environments. Previous studies suggested the existence of environmentally-adapted E. coli populations (van Elsas et al., 2011; Jang et al., 2017). Multidrug resistant $E$. coli have been found in mangrove estuaries (Ghaderpour et al., 2015). The contamination of this lowanthropized environment was attributed to antibiotic release and human activities. Petit et al. (2017) found different distributions of $E$. coli population depending on the presence of cattle farm near the river. Overall, E. coli from human and animal effluents do not appear to be disadvantaged in environments and specific areas such as wetlands or mangrove estuaries which features drastically differ from those in the vertebrate intestine. In other words, the E. coli population in wetlands seems to be a dilution of the E. coli population found in human and animal guts. It reflects either the survival of $E$. coli of mammal origin in the environment and/or the permanent release of these contaminants in the environment. As the phylogrouping does not fully overlap the isolate origin, we cannot track the sources of the bacterial contamination with certainty.

\section{CONCLUSION}

We found that a high proportion of the E. coli isolates retrieved in low-anthropized wetlands were probably human-associated. The similar population structures found in clinical settings, WWTPs and the environment suggest that E. coli released in the environment can reach and survive in specific areas like wetlands. 


\section{DATA AVAILABILITY STATEMENT}

All datasets presented in this study are included in the article/Supplementary Material.

\section{AUTHOR CONTRIBUTIONS}

$\mathrm{DM}, \mathrm{CH}, \mathrm{GB}, \mathrm{XB}$, and $\mathrm{DH}$ conceived and designed the experiments and wrote the manuscript. DM, MB, JC, and MR

\section{REFERENCES}

Alikhan, N.-F., Zhou, Z., Sergeant, M. J., and Achtman, M. (2018). A genomic overview of the population structure of Salmonella. PLoS Genet. 14:e1007261. doi: 10.1371/journal.pgen.1007261

Arthaud, F., Vallod, D., Robin, J., Wezel, A., and Bornette, G. (2013). Short-term succession of aquatic plant species richness along ecosystem productivity and dispersal gradients in shallow lakes. J. Veg. Sci. 24, 148-156. doi: 10.1111/j.16541103.2012.01436.x

Balière, C., Rincé, A., Blanco, J., Dahbi, G., Harel, J., Vogeleer, P., et al. (2015). Prevalence and characterization of shiga toxin-producing and enteropathogenic Escherichia coli in shellfish-harvesting areas and their watersheds. Front. Microbiol. 6:1356. doi: 10.3389/fmicb.2015.01356

Berthe, T., Ratajczak, M., Clermont, O., Denamur, E., and Petit, F. (2013). Evidence for coexistence of distinct Escherichia coli populations in various aquatic environments and their survival in estuary water. Appl. Environ. Microbiol. 79, 4684-4693. doi: 10.1128/AEM.00698-13

Bornette, G., Guerlesquin, M., and Henry, C. P. (1996). Are the characeae able to indicate the origin of groundwater in former river channels? Vegetation 125, 207-222. doi: 10.1007/BF00044652

Bornette, G., and Large, A. R. G. (1995). Groundwater-surface water ecotones at the upstream part of confluences in former river channels. Hydrobiologia 310, 123-137. doi: 10.1007/BF00015531

Bréchet, C., Plantin, J., Sauget, M., Thouverez, M., Talon, D., Cholley, P., et al. (2014). Wastewater treatment plants release large amounts of extendedspectrum $\beta$-lactamase-producing Escherichia coli into the environment. Clin. Infect. Dis. 58, 1658-1665. doi: 10.1093/cid/ciu190

Brookes, J. D., Antenucci, J., Hipsey, M., Burch, M. D., Ashbolt, N. J., and Ferguson, C. (2004). Fate and transport of pathogens in lakes and reservoirs. Environ. Int. 30, 741-759. doi: 10.1016/j.envint.2003.11.006

Cabral, J. P. S. (2010). Water microbiology. Bacterial pathogens and water. Int. J. Environ. Res. Public. Health 7, 3657-3703. doi: 10.3390/ijerph7103657

Cao, V., Lambert, T., Nhu, D. Q., Loan, H. K., Hoang, N. K., Arlet, G., et al. (2002). Distribution of extended-spectrum $\beta$-lactamases in clinical isolates of Enterobacteriaceae in Vietnam. Antimicrob. Agents Chemother. 46, 3739-3743. doi: 10.1128/AAC.46.12.3739-3743.2002

Clermont, O., Christenson, J. K., Denamur, E., and Gordon, D. M. (2013). The Clermont Escherichia coli phylo-typing method revisited: improvement of specificity and detection of new phylo-groups. Environ. Microbiol. Rep. 5, 58-65. doi: 10.1111/1758-2229.12019

Clermont, O., Dixit, O. V. A., Vangchhia, B., Condamine, B., Dion, S., BridierNahmias, A., et al. (2019). Characterization and rapid identification of phylogroup $\mathrm{G}$ in Escherichia coli, a lineage with high virulence and antibiotic resistance potential. Environ. Microbiol. 21, 3107-3117. doi: 10.1111/14622920.14713

Coque, T. M., Novais, Â, Carattoli, A., Poirel, L., Pitout, J., Peixe, L., et al. (2008). Dissemination of clonally related Escherichia coli strains expressing extendedspectrum $\beta$-lactamase CTX-M-15. Emerg. Infect. Dis. 14, 195-200. doi: 10.3201/ eid1402.070350

Day, M. J., Hopkins, K. L., Wareham, D. W., Toleman, M. A., Elviss, N., Randall, L., et al. (2019). Extended-spectrum $\beta$-lactamase-producing Escherichia coli in human-derived and foodchain-derived samples from England, Wales, and Scotland: an epidemiological surveillance and typing study. Lancet Infect. Dis. 19, 1325-1335. doi: 10.1016/S1473-3099(19)30273-7 carried out the experiments. DM, CH, CC, and BV analyzed the data. All authors contributed to the article and approved the submitted version.

\section{SUPPLEMENTARY MATERIAL}

The Supplementary Material for this article can be found online at: https://www.frontiersin.org/articles/10.3389/fmicb. 2020.552566/full\#supplementary-material]

Dhanji, H., Murphy, N. M., Akhigbe, C., Doumith, M., Hope, R., Livermore, D. M., et al. (2011). Isolation of fluoroquinolone-resistant O25b:H4-ST131 Escherichia coli with CTX-M-14 extended-spectrum $\beta$-lactamase from UK river water. J. Antimicrob. Chemother. 66, 512-516. doi: 10.1093/jac/dkq472

Escobar-Páramo, P., Grenet, K., Le Menac'h, A., Rode, L., Salgado, E., Amorin, C., et al. (2004). Large-scale population structure of human commensal Escherichia coli isolates. Appl. Environ. Microbiol. 70, 5698-5700. doi: 10.1128/AEM.70.9. 5698-5700.2004

Ghaderpour, A., Ho, W. S., Chew, L.-L., Bong, C. W., Chong, V. C., Thong, K.L., et al. (2015). Diverse and abundant multi-drug resistant E. coli in Matang mangrove estuaries, Malaysia. Front. Microbiol. 6:977. doi: 10.3389/fmicb.2015. 00977

Gibreel, T. M., Dodgson, A. R., Cheesbrough, J., Fox, A. J., Bolton, F. J., and Upton, M. (2012). Population structure, virulence potential and antibiotic susceptibility of uropathogenic Escherichia coli from Northwest England. J. Antimicrob. Chemother. 67, 346-356. doi: 10.1093/jac/dkr451

Gordon, D. M., and Cowling, A. (2003). The distribution and genetic structure of Escherichia coli in Australian vertebrates: host and geographic effects. Microbiology 149, 3575-3586. doi: 10.1099/mic.0.26486-0

Hayashi, W., Ohsaki, Y., Taniguchi, Y., Koide, S., Kawamura, K., Suzuki, M., et al. (2018). High prevalence of blaCTX-M-14 among genetically diverse Escherichia coli recovered from retail raw chicken meat portions in Japan. Int. J. Food Microbiol. 284, 98-104. doi: 10.1016/j.ijfoodmicro.2018.08.003

Henriot, C. P., Martak, D., Cuenot, Q., Loup, C., Masclaux, H., Gillet, F., et al. (2019). Occurrence and ecological determinants of the contamination of floodplain wetlands with Klebsiella pneumoniae and pathogenic or antibioticresistant Escherichia coli. FEMS Microbiol. Ecol. 95:fiz097. doi: 10.1093/femsec/ fiz097

Hocquet, D., Muller, A., and Bertrand, X. (2016). What happens in hospitals does not stay in hospitals: antibiotic-resistant bacteria in hospital wastewater systems. J. Hosp. Infect. 93, 395-402. doi: 10.1016/j.jhin.2016.01.010

Jang, J., Hur, H.-G., Sadowsky, M. J., Byappanahalli, M. N., Yan, T., and Ishii, S. (2017). Environmental Escherichia coli: ecology and public health implications-a review. J. Appl. Microbiol. 123, 570-581. doi: 10.1111/jam. 13468

Jang, J., Suh, Y.-S., Di, D. Y. W., Unno, T., Sadowsky, M. J., and Hur, H.G. (2013). Pathogenic Escherichia coli strains producing extended-spectrum $\beta$-lactamases in the Yeongsan River basin of South Korea. Environ. Sci. Technol. 47, 1128-1136. doi: 10.1021/es303577u

John, D. E., and Rose, J. B. (2005). Review of factors affecting microbial survival in groundwater. Environ. Sci. Technol. 39, 7345-7356. doi: 10.1021/es 047995w

Johnson, J. R., Murray, A. C., Gajewski, A., Sullivan, M., Snippes, P., Kuskowski, M. A., et al. (2003). Isolation and molecular characterization of nalidixic acid-resistant extraintestinal pathogenic Escherichia coli from retail chicken products. Antimicrob. Agents Chemother. 47, 2161-2168. doi: 10.1128/AAC.47. 7.2161-2168.2003

Kallonen, T., Brodrick, H. J., Harris, S. R., Corander, J., Brown, N. M., Martin, V., et al. (2017). Systematic longitudinal survey of invasive Escherichia coli in England demonstrates a stable population structure only transiently disturbed by the emergence of ST131. Genome Res. 27, 1437-1449. doi: 10.1101/gr.2166 06.116

Ludden, C., Raven, K. E., Jamrozy, D., Gouliouris, T., Blane, B., Coll, F., et al. (2019). One health genomic surveillance of Escherichia coli demonstrates 
distinct lineages and mobile genetic elements in isolates from humans versus livestock. mBio 10:e2693-18. doi: 10.1128/mBio.02693-18

Mabilat, C., and Courvalin, P. (1990). Development of "oligotyping" for characterization and molecular epidemiology of TEM beta-lactamases in members of the family Enterobacteriaceae. Antimicrob. Agents Chemother. 34, 2210-2216. doi: 10.1128/aac.34.11.2210

Manges, A. R., Geum, H. M., Guo, A., Edens, T. J., Fibke, C. D., and Pitout, J. D. D. (2019). Global extraintestinal pathogenic Escherichia coli (ExPEC) lineages. Clin. Microbiol. Rev. 32, 1-25. doi: 10.1128/CMR.00135-18

Massot, M., Daubié, A.-S., Clermont, O., Jaureguy, F., Couffignal, C., Dahbi, G., et al. (2016). Phylogenetic, virulence and antibiotic resistance characteristics of commensal strain populations of Escherichia coli from community subjects in the Paris area in 2010 and evolution over 30 years. Microbiology 162, 642-650. doi: $10.1099 /$ mic. 0.000242

Michael, I., Rizzo, L., McArdell, C. S., Manaia, C. M., Merlin, C., Schwartz, T., et al. (2013). Urban wastewater treatment plants as hotspots for the release of antibiotics in the environment: a review. Water Res. 47, 957-995. doi: 10.1016/ j.watres.2012.11.027

Moissenet, D., Salauze, B., Clermont, O., Bingen, E., Arlet, G., Denamur, E., et al. (2010). Meningitis caused by Escherichia coli producing TEM-52 extended-spectrum $\beta$-lactamase within an extensive outbreak in a neonatal ward: epidemiological investigation and characterization of the strain. J. Clin. Microbiol. 48, 2459-2463. doi: 10.1128/JCM.00529-10

Mughini-Gras, L., Dorado-García, A., van Duijkeren, E., van den Bunt, G., Dierikx, C. M., Bonten, M. J. M., et al. (2019). Attributable sources of communityacquired carriage of Escherichia coli containing $\beta$-lactam antibiotic resistance genes: a population-based modelling study. Lancet Planet. Health 3, e357-e369. doi: 10.1016/S2542-5196(19)30130-5

Nicolas-Chanoine, M.-H., Bertrand, X., and Madec, J.-Y. (2014). Escherichia coli ST131, an intriguing clonal group. Clin. Microbiol. Rev. 27, 543-574. doi: 10. 1128/CMR.00125-13

Niu, J., and Phanikumar, M. S. (2015). Modeling watershed-scale solute transport using an integrated, process-based hydrologic model with applications to bacterial fate and transport. J. Hydrol. 529, 35-48. doi: 10.1016/j.jhydrol.2015. 07.013

Oberlé, K., Capdeville, M.-J., Berthe, T., Budzinski, H., and Petit, F. (2012). Evidence for a complex relationship between antibiotics and antibiotic-resistant Escherichia coli: from medical center patients to a receiving environment. Environ. Sci. Technol. 46, 1859-1868. doi: 10.1021/es203399h

Park, Y., Pachepsky, Y., Shelton, D., Jeong, J., and Whelan, G. (2016). Survival of manure-borne and fecal coliforms in soil: temperature dependence as affected by site-specific factors. J. Environ. Qual. 45, 949-957. doi: 10.2134/jeq2015.08. 0427

Pärnänen, K. M. M., Narciso-da-Rocha, C., Kneis, D., Berendonk, T. U., Cacace, D., Do, T. T., et al. (2019). Antibiotic resistance in European wastewater treatment plants mirrors the pattern of clinical antibiotic resistance prevalence. Sci. Adv. 5:eaau9124. doi: 10.1126/sciadv.aau9124
Petit, F., Clermont, O., Delannoy, S., Servais, P., Gourmelon, M., Fach, P., et al. (2017). Change in the structure of Escherichia coli population and the pattern of virulence genes along a rural aquatic continuum. Front. Microbiol. 8:609. doi: 10.3389/fmicb.2017.00609

Pitout, J. D., and Laupland, K. B. (2008). Extended-spectrum $\beta$-lactamaseproducing Enterobacteriaceae: an emerging public-health concern. Lancet Infect. Dis. 8, 159-166. doi: 10.1016/S1473-3099(08)70041-0

Price, M. N., Dehal, P. S., and Arkin, A. P. (2009). FastTree: computing large minimum evolution trees with profiles instead of a distance matrix. Mol. Biol. Evol. 26, 1641-1650. doi: 10.1093/molbev/msp077

Price, M. N., Dehal, P. S., and Arkin, A. P. (2010). FastTree 2-approximately maximum-likelihood trees for large alignments. PLoS One 5:e9490. doi: 10. 1371/journal.pone.0009490

Riley, L. W. (2014). Pandemic lineages of extraintestinal pathogenic Escherichia coli. Clin. Microbiol. Infect. Off. Publ. Eur. Soc. Clin. Microbiol. Infect. Dis. 20, 380-390. doi: 10.1111/1469-0691.12646

Tenaillon, O., Skurnik, D., Picard, B., and Denamur, E. (2010). The population genetics of commensal Escherichia coli. Nat. Rev. Microbiol. 8, 207-217. doi: $10.1038 /$ nrmicro2298

van Elsas, J. D., Semenov, A. V., Costa, R., and Trevors, J. T. (2011). Survival of Escherichia coli in the environment: fundamental and public health aspects. ISME J. 5, 173-183. doi: 10.1038/ismej.2010.80

Walk, S. T. (2015). The "cryptic" Escherichia. EcoSal Plus 6. doi: 10.1128/ecosalplus. ESP-0002-2015

Wirth, T., Falush, D., Lan, R., Colles, F., Mensa, P., Wieler, L. H., et al. (2006). Sex and virulence in Escherichia coli: an evolutionary perspective. Mol. Microbiol. 60, 1136-1151. doi: 10.1111/j.1365-2958.2006. 05172.x

Yu, G., Lam, T. T.-Y., Zhu, H., and Guan, Y. (2018). Two methods for mapping and visualizing associated data on phylogeny using ggtree. Mol. Biol. Evol. 35, 3041-3043. doi: 10.1093/molbev/msy194

Yu, G., Smith, D. K., Zhu, H., Guan, Y., and Lam, T. T.-Y. (2017). ggtree: an $r$ package for visualization and annotation of phylogenetic trees with their covariates and other associated data. Methods Ecol. Evol. 8, 28-36. doi: 10.1111/ 2041-210X.12628

Conflict of Interest: The authors declare that the research was conducted in the absence of any commercial or financial relationships that could be construed as a potential conflict of interest.

Copyright (C) 2020 Martak, Henriot, Broussier, Couchoud, Valot, Richard, Couchot, Bornette, Hocquet and Bertrand. This is an open-access article distributed under the terms of the Creative Commons Attribution License (CC BY). The use, distribution or reproduction in other forums is permitted, provided the original author(s) and the copyright owner(s) are credited and that the original publication in this journal is cited, in accordance with accepted academic practice. No use, distribution or reproduction is permitted which does not comply with these terms. 